\title{
Innovative care in Latin America: definition, justification and ethical principles
}

Felicitas S. Holzer ${ }^{1}$ and Ignacio D. Mastroleo ${ }^{2}$

\begin{abstract}
The term "innovation" or "innovative care" has recently gained attention in the context of the use of novel and not yet fully validated medical interventions and technologies. Most notably, there have been various incidences of medical activities insufficiently validated for its regular use in healthcare that fall into this category, such as stem cell treatments, genome sequencing for diagnostic purposes, or novel reproductive technologies. Latin American countries are among the places where new and non-validated medical activities take place, notably due to a lack of clear regulations and the poor support of authorities of existent legal and ethical guidelines, which is driven by "hidden battles" on the moral status of certain interventions. The increasing importance of innovative care underlines the importance of developing a general framework for these practices. Therefore, the present chapter scrutinizes this nascent field of inquiry in Latin America and offers a conceptual framework for innovation as well as its ethical justification. As we will argue, an important use of the term "innovation" or "innovative care" is best interpreted as "new non-validated practice" and not a research activity. Then, we will defend that responsible innovation understood as responsible new
\end{abstract}

\footnotetext{
${ }^{1}$ Sorbonne University Paris, University of Buenos Aires, National Scientific and Technical Research Council (CONICET) and the Bioethics Program at FLACSO Argentina.

Email: felicitasholzer@gmx.de.

${ }^{2}$ National Scientific and Technical Research Council (CONICET), University of Buenos Aires, and Bioethics Program at FLACSO Argentina.

Email: ignaciomastro@gmail.com
} 
non-validated practice is ethically permissible and poses an acceptable medical option if done in exceptional circumstances -where no reasonable alternatives can be provided to an individual patient- and following special ethical principles. Finally, we focus on the peculiarities and specific difficulties the concept of new non-validated practice poses to the Latin American context. We will conclude the chapter by some remarks and recommendations we draw from our analysis for individual patients, doctors, and societies in Latin America.

\section{Keywords}

Responsible innovation. New non-validated practice. Research and practice distinction in the Belmont Report. New health technologies in Latin America. Stem cell therapies.

\section{How to cite}

Holzer, F., \& Mastroleo, I. (2019). Innovative care in Latin America: definition, justification and ethical principles. Preprint. In M. Hevia \& E. Rivera López (Eds.), Controversies in Latin American Bioethics. Springer. Zenodo Preprint, version 1.0.0, $25^{\text {th }}$ February 2019, https://doi.org/10.5281/zenodo. 2577257

\section{Preprint version}

Preprint version 1.0.0, 25 $5^{\text {th }}$ February 2019 


\section{Introduction}

This chapter introduces our original conceptual framework of new non-validated practice (Holzer and Mastroleo, 2018, Mastroleo and Holzer, 2018) to give a precise definition of one important meaning of the term "innovation" or "innovative care". In the current literature of innovative care frameworks, the paradigmatic case of an ethical and successful new, but insufficiently validated medical intervention has been the application of stem cell treatment in umbilical cord blood transplant outside sound clinical trials in the late 1980s to save the life of Mathew Farrow, a 5-year-old child with Fanconi's anemia (Sugarman 2012, Taylor 2010). This treatment has paved the way for valuable clinical procedures, nowadays validated and established in clinical routine. However, recent incidences of an unsuccessful insufficiently regulated and, most probably, unethical use of innovative care point to the substantive risks associated with new and unproven interventions outside sound research. For instance, the case of Jim Gass -that will be discussed in more detail in the next section- provoked an outcry in international media. Jim Gass had previously undergone several stem cell therapies at clinics in Mexico, China and Argentina, paying tens of thousands of dollars each time for injections in an attempt to recover from a stroke. Eventually, Gass developed a tumor in his lower spinal column, a mass that was made up of abnormal, primitive cells that were growing aggressively.

Here, we argue that the same complex situation could be recognized in other cases of new and insufficiently validated clinical interventions, such as genome editing and mitochondrial replacement techniques. Successful and ethical cases of innovation illustrate the potential benefits of innovative clinical interventions and are the basis of defending this pathway for 
patients without a validated medical alternative. However, unfortunate and irresponsible cases also show that allowing for the unrestricted use of new and insufficiently proven interventions may have untoward consequences for both individuals and society. Consequently, new non-validated practice needs to be treated with caution because neither research nor practice regulations protect patients that undergo innovative care.

Moreover, Latin American countries are among the places where an increased application of new and non-validated medical activities can be observed, notably due to a lack of clear regulations and poor support of authorities of existent legal and ethical guidelines (Rosemann et al. 2018, Chan and Medina-Arellano 2016). Therefore, we will first of all outline in this chapter, and in particular section II, exemplary cases that have taken place in Latin America, and more specifically in Mexico and Argentina. Here, we will discuss three potential novel therapeutic biomedical interventions, namely, stem cell therapies, gene editing, and Mitochondrial Replacement Technologies (MRTs), as well as a novel and yet non-validated diagnostic tool, that is, genome sequencing for patients with rare diseases.

Section III is dedicated to a comprehensive analysis of what the current literature in research ethics calls "innovation" (Taylor 2010, Sugarman 2012, London 2006) and what we define as "new non-validated practice" in our conceptual framework (Holzer and Mastroleo, 2018; Mastroleo and Holzer, 2018).

In section IV, we will address epistemic and ethical concerns related to our neutral conceptual framework of innovation as new non-validated practice. In particular, we will argue that the health needs of seriously ill patients with no reasonable medical alternatives ethically justify and occasionally even demand the application of new non-validated practices 
outside clinical trials or other sound research activities. However, we will also point to the danger that new clinical interventions with an insufficient level of validation for individual patients may "crowd out" sound clinical research or other forms of research. Thus, there may be good ethical and epistemic reasons to regulate the use of new non-validated practice regarding the impact clinical decision may have on future patients and society.

In section $\mathrm{V}$, we then identify and outline commonly defended ethical principles that govern the use of responsible new non-validated practices, which has been so far described as "responsible innovation" in the literature (Sugarman 2012, ISSCR 2016). The work of the principles is to distinguish between responsible or irresponsible cases of innovative care but only as a logical third step after neutrally defining what is innovation within our conceptual framework (section III) and giving a justification that is an ethically permissible activity (section IV).

In the last section VI, our conclusion, we finally bring together the outlined cases of applied new non-validated practices in Latin America and our conceptual analysis of the other sections. Here, we will mainly focus on the peculiarities and specific difficulties the category of new non-validated practice poses to the Latin American context, such as e.g. the strong influence on law and regulations by the Catholic Church. We will conclude the chapter by some remarks and recommendations we draw from our analysis for individual patients, doctors, and societies in Latin America. 


\section{Exemplary cases of innovation and its context in Latin America}

Before developing a formal definition of innovation as "new non-validated practice" in the clinical context, we want to outline four exemplary cases. Even though we cannot provide detailed case studies, we want to capture the major intuitions that will be furthermore developed in our conceptual framework. We decide to introduce different cases that cover responsible, irresponsible, successful and failed innovative care. This already hints at our further goal to provide a "neutral" framework of innovation, independent of its outcomes and responsible conduction.

We argue that new non-validated practice comprises therapeutic, preventive, and diagnostic interventions. Nevertheless, we will only discuss three potential novel therapeutic biomedical interventions, namely, stem cell therapies, gene editing, and Mitochondrial Replacement Technologies (MRTs), as well as a novel and yet non-validated diagnostic tool, and more precisely, genome sequencing for patients with rare diseases. Here, we will focus on case examples that took place in the Latin American context, most notably in Argentina and Mexico.

After looking into the cases, we will have a better idea about the context in which these take place. As we will further outline, there are at least two specific contextual characteristics with respect to the use of new non-validated practice in these countries. First, the regulatory landscape that is often vague and, second, the influence by the Catholic Church on the deliberation regarding the application of new biomedical technologies, especially in the field of embryonic stem cell research and reproductive technologies. Following Luna and Salles (2010), we may advance the hypothesis that both characteristics regarding the Latin 
American context are deeply connected, as 'unsolved' metaphysical conceptions and doctrines have been impeding a clear public position in the form of clear-cut regulations. ${ }^{3}$

\subsection{Stem cell therapeutic interventions}

Stem cell treatments are on the rise not only in Latin America, but also all over the world. Innovative stem cell therapies, such as the first successful bone marrow transplantation in the 1990s initiated this global trend (Sugarman 2012). However, there are current concerns about cases, as the following one:

According to Gina Kolata (2016), Jim Gass's problems began on May 10, 2009, when he woke up with a terrible headache. "He tried to get out of bed and fell to the floor, unable to move. He'd had a stroke. Two years later, he was able to walk only with a leg brace and a cane". After that, Jim Gass had several stem cell therapies at clinics in Mexico, China and Argentina, paying tens of thousands of dollars each time for injections to recover from a stroke he had in 2009. The total cost including travel expenses reached 300.000 US dollars. Eventually, Jim Gass developed a tumor in his lower spinal column. The following tests have shown that the tumor mass was made up of abnormal, primitive cells that were growing aggressively (Kolata, 2016). In Argentina, Gass received interventions made from his own stem cells at a private clinic. ${ }^{4}$ In México, he received an injection of fetal cells shipped from Russia (Kolata, 2016). As Kolata describes Mr. Gass’s current condition:

After the stroke, Mr. Gass lived independently although his left arm was useless and his left leg weak. Now, however, with the foreign body in his spine, he is paralyzed

\footnotetext{
3 As Luna and Salles argue "[...] legislative silence regarding stem cell research may not necessarily be a manifestation of a legal/moral disconnection, but rather a survival strategy for navigating the long and heated battle on the moral status of the embryo and the kind of treatment it deserves" (Luna and Salles 2010, p. 120). ${ }^{4} \mathrm{Jim}$ Gass, personal communication 30 $0^{\text {th }}$ June 2016.
} 
from the neck down, except for his right arm. He needs a hoist to move from his bed to a wheelchair, and his doctors do not know how to stop the tumor from growing. (Kolata 2016).

The case of Jim Gass provoked an outcry in international media that illustrated a growing concern about the number of stem cell tourists worldwide. The New York Times article reports that there is an increasing trend of clinics in countries with low regulation standards for stem cell therapies, including Latin American countries, such as Argentina and Mexico. Promises are often made to treat and cure patients' diseases, such as muscular dystrophy, Alzheimer's, Parkinson's, or spinal cord injuries as well as strokes by injecting patients with stem cells.

\subsection{Genome editing therapeutic interventions}

New "genome editing" techniques, most notably the CRISPR/Cas system have provoked a huge interest in this research area. "Gene" or "genome editing" technologies are molecular complexes that can achieve a specific targeted modification of the DNA sequence.

CRISPR/Cas, ZFNs and TALENs are editing systems that are nowadays applied, investigated, and widely discussed (Chan and Medina-Arellano 2016, Rasmussen 2015). The possibilities of applying these new techniques include among others the combination of genome editing and stem cell science for a new generation of somatic gene therapies. According to Chan and Medina-Arellano (2016), the therapeutic potential of CRISPR/Cas is likely to stimulate demand from patient groups to use these techniques in cases of health conditions where no effective treatment is available. The possibility of germ line genetic modification and its associated ethical concerns, such as the creation of genetically modified human embryos, has however overshadowed the debate about potentially new, but yet untested therapeutic interventions. This again supports the hypothesis that there exist "hidden 
battles" between scientists and the Catholic Church regarding the debate on the moral status of the embryo, which affects the initiation of regulatory and juridical processes for certain interventions (Luna and Salles 2010).

Shedding more light on the regulatory, economic, scientific, and social landscape for the use, research, and implementation of new technologies in the biomedical field, Chan and MedinaArellano (2016) investigate the case of Mexico. They show e.g. that genome editing technologies have raised debates on conflicting arguments that have heavily influenced the regulations of such technologies. These interest comprise international trade, economic development, compliance with international governance, food security, and environmental and biosafety concerns. In particular, gene editing regarding agriculture and the environment has triggered and exacerbated such conflicts around the Law on Biosafety.

However, human generic modifications in 'human beings' are not considered 'organisms' in the sense of the Law on Biosafety (Chan and Medina-Arellano 2016, Ley de Bioseguridad de Organismos Genéticamente Modificados 2005, Article 3), which takes out from the jurisdiction the human genome, stem cell cultures, and the modification of human germ cells. These issues fall under the General Health Act and international treaties and regulatory frameworks, such as the guidelines by the International Society for Stem Cell Research (ISSCR, 2016). Yet, regulatory frameworks rarely address the clinical application of stem cell derived products, including cells that have undergone gene editing. In practice, experimental therapies with stem cells or stem cell derived products are easily available and commercialised. Loopholes in the regulatory system permit scientists to avoid regulation by switching terms for activities. Thus, although commercialisation of tissues and cells themselves is prohibited, there are ways to sell the procedure, isolation, processing of the cells, which creates a market in practice (Chan and Medina-Arellano 2016: 431). This leaves potential patients exposed to physical and financial burdens and risks when undergoing stem 
cell-based therapies, as demonstrated in problematic cases, such as the one of Jim Gass. Applying these lessons for the regulation of past new forms of biotechnological innovation and in particular stem cell treatments, Chan and Medina-Arellano (2016) conclude that the application of gene editing technologies could face similar problems in the future.

So far, international regulations have been a patchwork regarding different countries and the scientific fields involved. In Mexico in particular, laws are vague and broad, which makes a juridical case by case analysis of the implementations of new biomedical technologies difficult. Especially with regard to innovative experimental therapies for desperate patients with no alternatives, countries with low regulatory burdens seem attractive. Medical tourisms and international marketing show that the problem of regulating yet unproven treatments has an impact on an international level. Providers have shown to make use of regulatory differences in different countries.

\subsection{Mitochondrial replacement techniques}

In 2016, the first baby was born to a Jordanian couple after a mitochondrial replacement technique (MRT, specifically maternal spindle transfer). The mitochondrial replacement procedure happened in Mexico where scientists from the U.S. carried out the procedure. Dr. John Zhang who is leading the scientific group is the founder and medical director of the New Hope Fertility Clinic in New York City. The couple has consulted his clinic after two of their children had died from Leigh's syndrome, a neuro-metabolic disorder that affects the central nervous system (Palacios-Gonzalez and Medina-Arellano 2017a, 2017b).

Mitochondrial DNA diseases occur when mitochondria with deleterious DNA mutations exist and energy is insufficiently supplied to somatic cells (see Palacios-Gonzalez and Medina- 
Arellano 2017a:6). These deleterious mutations can be inherited or acquired during life and affect all (homoplasmy) or only some (heteroplasmy) mitochondrial genomes. Women with homoplasmic deleterious mutations will always pass this condition across the whole mitochondrial genome to their biological children and those with heteroplasmic mutations will pass a mixture of healthy and unhealthy mitochondria. However, the severity of Mitochondrial DNA disease depends on the type of mutation and the number of mitochondria affected. MRTs offer a technology to these women to reproduce a healthy biological child. Thus, in all cases in which women wish to reproduce and the mitochondrial DNA disease is severe, MRTs pose a new and not yet fully validated intervention for women without other alternatives.

MRTs basically comprise two main techniques. In the so called "pronuclear transfer" (PNT), two zygotes are created (see Palacios-Gonzalez and Medina-Arellano 2017a: 8-9). One is created with the intending parents' gametes (or the intending mother's egg and a donor's sperm). The second is created with an egg that has been donated from a woman without mitochondrial DNA disease and the intending father's (or donor's) sperm. After fertilization, the nuclear material of the egg and sperm are enclosed in different membranes (pronuclei) and removed from both zygotes during the first 24 hours. The pronuclei of the donor's nuclear material and the enucleated cell with the intending mother's oocyte are discarded. The intending parent's pronuclei are transferred to the enucleated zygote of the donor's egg. In this way, the healthy donor's mitochondria and the nuclear material of the intending parents are combined. Another procedure is the "maternal spindle transfer" (MST) where oocytes are obtained from the intending mother and a healthy donor. The chromosomes of both oocytes during cell division are removed and the donor's chromosomes and the intending mother's enucleated oocyte are discarded. Then, the intending mother's 
chromosomes are transferred to the donor's enucleated oocyte and the new egg with healthy mitochondria is fertilized in vitro.

MRTs have been only legal in the UK since 2015. In the U.S., the National Academy of Sciences panel also recommended accepting MRTs in certain limitations, but the Congress blocked the novel techniques for prevention of maternal transmissions of mitochondrial DNA diseases, meaning that the FDA was hindered to consider these techniques in certain exceptional circumstances (Palacios-Gonzalez and Medina-Arellano 2017a, 2017b). Due to these regulatory issues, Dr. Zhang and colleagues decided to carry out the procedure in Mexico. To do this, he opened two branches of his fertility clinic in the State of Mexico City and in the city of Guadalajara in the state of Jalisco. According to public statements and the abstract of a conference paper for the American Society for Reproductive Medicine 2016 Scientific Congress in 2016, Dr. Zhang (2016) claimed that he performed the MRT procedure in Mexico because "there are no rules", where he most likely referred to the rather 'loose' regulations in Mexico. In fact, even though there are laws regulating reproductive technologies, they are fairly loose and moreover, do neither explicitly allow nor forbid MRT. The legality of performing the procedure in Mexico has been, however, questioned by Palacios-Gonzalez and Medina-Arellano (2017). They claim that a revised reading of the legal framework applied to the discussed case would not have permitted MRT under the regulations of the General Health Law on Health Research. According to this article 56 (Ley general de Salud en Materia de Investigación para la Salud 1987), research on assisted fertilization is only permitted when it solves sterility problems that cannot be solved otherwise. However, the woman was fertile at the point in time when Dr. Zhang performed the procedure. $^{5}$

\footnotetext{
${ }^{5}$ This is Palacios-Gonzalez' and Medina-Arellano's reading of the general Health Act., which might be also, in our opinion, interpreted differently. The original text is the following: "La investigación sobre fertilización
} 


\subsection{Genome sequencing as diagnostic tools for individual patients}

Examples of using new and unproven interventions outside sound clinical research activities are not limited to therapeutic procedures, such as the above-mentioned exemplary cases of stem cell therapies, gene editing, or MRTs. They also include diagnostic interventions. Genome sequencing technologies, including whole genome and whole exome sequencing, for patients with rare diseases is a recent exemplary case of a new insufficiently validated diagnostic intervention used outside sound clinical research activities. Patients who suffer from rare diseases often face long and burdensome diagnostic procedures over several decades. Decoding the genetic causes of disease is crucial in order to target potential therapies for rare diseases.

In Argentina, diagnostic procedures for rare diseases are preformed and established as 'research activity' under the ethical principles for research (CIOMS-WHO 2016) and regulatory system of the Argentine Health Authority ANMAT (Administración Nacional de Medicamentos, Alimentos y Tecnología) (ANMAT 2010, MSAL 2011). Decreasing costs for sequencing technologies has paved the way for extended research and diagnostic applications of these technologies. For instance, Cordoba et al. (2018) report a diagnostic yield regarding rare mutations in patients with unknown neurological disorders of around $40 \%$ in a cohort of 40 patients that have undergone whole genome and exome sequencing methods (Córdoba et al. 2018, see Kaufmann 2013, see Kauffman and Turjanski 2015). Previous studies had

\footnotetext{
asistida sólo será admisible cuando se aplique a la solución de problemas de esterilidad que no se puedan resolver de otra manera, respetándose el punto de vista moral, cultural y social de la pareja, aun si éste difiere con el de investigador." ["The research on assisted fertilization will only be admissible when applied to the solution of sterility problems that cannot be solved in another way, while respecting the moral, cultural and social point of view of the couple, even if this differs from the point of view of the researcher."] (Article 56, Ley general de Salud en Materia de Investigación para la Salud 1987, translated).
} 
revealed a diagnostic rate of about $30 \%$ in neuro-genetic disorders regarding results of large series that have included other medical conditions as well (Cordoba 2018).

Due to the lack of national guidelines, Argentine geneticists base the report of findings to patients most notably on the recommendations by the National Bioethics Advisory Commission (NBAC 1999) and the American College of Medical Genetics (Committee on Bioethics 2013), despite their contradictory instructions. Still, it remains questionable whether the application of sequencing technologies for yet non-validated interventions should be labelled 'research'. In particular, in cases where the main aim is not to contribute to general knowledge but to improve (not yet entirely validated) diagnostic tools for individual patients.

\subsection{Context in Latin America: the hidden battle hypothesis, effective regulation and the influence by the Catholic Church}

In this section, we would like to briefly highlight a peculiarity of the Latin American regulatory landscape and more precisely focus on the power of conservative voices most notably represented and put forward by the Catholic Church. Here we discuss the situation in Argentina, which can be, however, applied to other countries in Latin America. As an exemplary case, Luna and Salles (2010) dwell on the influence by the Catholic Church on the regulations of regenerative medicine, such as (embryonic) stem cell research in Argentina. They refer to an article by Shawn Harmon (2008) who had previously tried to contextualize the discussion on regulatory attempts for stem cell research in Argentina. According to him, the country has already taken many positive steps to build up its stem cell research capacity and has considerably advanced in the field. Based on that, he is interested in the translation of 
country-specific moral values held by Argentines into their legislation and regulatory guidelines.

According to the Luna and Salles (2010), the influence by the Church should not be underestimated. For instance, the document of Donum Vitae (Congregation for the Doctrine of the Faith 1987) clearly states that an embryo, from its first moment of its existence, demands morality and respect to the human being, as well as its spiritual totality. In a dogmatic but common interpretation of the text, there is no objective that could overrule the moral prohibition to destroy an embryo. Moreover, the Vatican's Instructions Dignitas Personae, launched in 2008 , holds that an embryo possesses 'the dignity proper to the person' and 'unconditional respect' is owed to 'every human being at every moment of his or her existence' (Congregation for the Doctrine of the Faith 1987). This has major implications, also for the recommendation for the use of embryonic stem cells:

"...the use of embryonic stem cells or differentiated cells derived from them - even when these are provided by other researchers through the destruction of embryos or when such cells are commercially available - presents serious problems from the standpoint of cooperation in evil and scandal." (Declaration on the Production and the Scientific and Therapeutic use of Human Embryonic Stem Cells 2000)

Harmon (2008) points to the juridical 'silence' on the status of embryos, which may implicitly permit research with embryonic stem cells. However, Luna and Salles (2010) argue that there is also a more conservative reading of existing law, namely that personhood can be attributed to an embryo, especially in the context of assisted reproductive technologies and reproductive health in general. Previously, conservative voices and lobbying in Argentina had lead to legal demands, such as the demand to have a lawyer acting as a legal guardian for cryo-preserver embryos at court (Luna and Salles 2010: 125). 
In Argentina, more than $80 \%$ of the people call themselves Catholic. Historically speaking, Luna and Salles (2010) claim that the Church influenced on the nation and citizens through its institutions and its presence in education and charity. This shaped the views on sexual rights and sexuality in general, meaning that legislation often followed the Church's view despite legislative changes regarding LGBT rights and assisted reproductive technologies (Luna 2018). Generally speaking, the Catholic Church is still one of the main stakeholders involved through their value schemes in the development of the regulatory landscapes for new and yet insufficiently proven biomedical interventions and technologies.

According to the Luna and Salles (2010), the growing importance of liberalism during the twentieth century did not stop the Catholic groups from proliferating and promoting Christian values. However, today's influence of the Church on the behaviour of individuals is not as easy to analyze. For instance, women widely use birth control methods and a considerable number of women have undergone abortion illegally until its recent legalization. Finally, one can increasingly hear voices that support stem cell research as a promising new opportunity for the country to achieve international recognition. But apart from the debate in which scientific interests and religious concerns clash, Luna and Salles (2010) consider women an underrepresented group in the debate in which feminist interests and concerns are frequently ignored.

\section{Definition: What is innovation as new non-validated practice?}

In a previous work, we defended that the term "innovation" in the context of clinical medicine (Brierley and Larcher, 2009; London, 2006; Mastroianni, 2006; Sugarman, 2012; Taylor, 2010) is best interpreted as "new non-validated practice", a term we define as the first or recent use of an intervention that introduces a significant change, with an insufficient level 
of safety or efficacy for regular healthcare, and with the main aim to benefit patients

(Mastroleo and Holzer, 2018). An important characteristic of our definition is that we frame innovation in morally neutral terms. This eventually separates the normative evaluation, i.e. ethical principles and justification of innovation from the activity itself, which allows for a reasonable disagreement about the scope of responsible innovation and leaves the "description" or "category" of the activity intact (Lipworth et al. 2018, Mastroleo and Holzer 2018).

In this section, we outline the arguments and results of this previous work to offer a sound explication of "new non-validated practice". More specifically, we revisit the distinction between research, validated practice and innovation made in the Belmont Report, as well as in Levine's definition of "non-validated practice". This preliminary conceptual analysis builds the basis to develop our conceptual framework of our definition of "innovation" as "new non-validated practice". Here, we depart from Levine's definition and argue that innovation is characterized by three features and not two, namely, novelty (new), validation (non-validated) and the intention to benefit individual patients (practice). Moreover, to avoid confusions, we introduce a taxonomy of four categories for interventions that logically follows from our definition.

\subsection{Traditional research ethics distinction between research, validated practice and innovation (non-validated practice)}

In order to address the concept of "non-validated practice", we would like to start by referring to the distinction in traditional research ethics between research, validated practice and nonvalidated practice. Following this distinction, non-validated practice is neither research nor validated medical practice. 
According to Beauchamp and Saghai's (2012) interpretation of the Belmont report, the National Commission for the Protection of Human Subjects of Biomedical and Behavioral Research (hereinafter National Commission) has established two classes of complex activities labeled "research" and "practice" as categories for medical interventions that are "logically distinguishable" (Beauchamp and Saghai 2012:55) from each other (although they may coexist). ${ }^{6}$ The first distinction the Belmont Report introduces is between research and what we here will call validated practice. This distinction has practical consequences because it draws a clear line between activities that should undergo review for the protection of research participants ("research") and activities that do not need this special consideration ("validated practice").

On the one hand, the Commission introduces "practice" we identify as "validated practice" for individual patients, and gives the following definition:

$[\mathrm{F}]$ or the most part, the term [validated] "practice" refers to interventions where: (P1) the purpose of an intervention is "to provide diagnosis, preventive treatment, or therapy"; (P2) the intervention is "designed solely to enhance the well-being of an individual patient or client" (though benefit to other persons is sometimes the goal); (P3) the intervention has "a reasonable expectation of success" (National Commission, 1978, as quoted in Beauchamp \& Saghai, 2012, p. 52, edited).

On the other hand, the National Commission defines research as follows:

\footnotetext{
${ }^{6}$ As Beauchamp and Saghai state Belmont Report "did not conclude that research and practice cannot be "carried on together when research is designed to evaluate the safety and efficacy of a therapy" [4, p. 4]. It affirmed that they can be so integrated. The segregation thesis is merely that research interventions are logically distinguishable from practice interventions. Belmont claimed no more than that an activity involving both research and practice components must be reviewed as research even if its primary goal is improving treatment for patients" (Beauchamp \& Saghai 2012:55). To understand how research and practice may coexist, see the concept of a component analysis developed by Weijer (2000), Weijer and Miller (2004).
} 
To qualify as research two conditions are central. The first is not a necessary

condition for all forms of research, but the second is a necessary condition: (R1) there is (in pertinent research methods) a formal protocol-controlled design to test a hypothesis; (R2) there is an organized design "to develop or contribute to generalizable [scientific] knowledge" (National Commission, 1978, as quoted in Beauchamp \& Saghai, 2012, p. 52).

The National Commission recommends that if an activity has an organized design "to develop or contribute to generalizable [scientific] knowledge", it should undergo a research review to protect human subjects, irrespective of the fact that the intervention or procedure is also intended to provide direct health benefits to the individual patient-subject (Levine, 2008, p. 217). This is a precautionary measure to prevent researchers from taking advantage of a loophole in the oversight system by applying investigational interventions under the label of "practice" to avoid the review process (Beauchamp \& Saghai, 2012, p. 43). In turn, an activity designed to enhance the well-being of an individual patient should be considered "practice". 7

\footnotetext{
${ }^{7}$ Belmont Report present a narrow and a wide definition of practice. Practice in a narrow sense refers to "the most part" of interventions "designed solely to enhance well-being of individual patients". However, the Belmont Report also defines the practice condition (P2) in a wider sense as "an intervention designed to enhance the well-being of a particular individual or groups of individuals" (National Commission 1979, note 1). This wide sense captures what Levine (1979) calls "practice for the benefits of others." That is, interventions designed only to enhance the well-being of others (e.g., blood donation and organ transplant) and interventions designed to enhance the well-being of an individual and others (e.g., vaccination) (Levine 1979, p. 22; National Commission 1979, note 1). The role of other persons as an essential part of the interventions complicates the assessment of the benefit-harm profile of an intervention because there is a need to evaluate the potential harms to other persons who are involved in the intervention. Nevertheless, these interventions should be considered practice, as they have the intention or main aim of enhancing the well-being of individual patients. According to Beauchamp and Saghai "The point of these qualifications was to reassure readers that activities designed to benefit others do not threaten the research-practice distinction the Commission had developed [...] Commissioners thought they had done enough for purposes of public policy by distinguishing research from practice, whatever those various forms of practice might turn out to be on a closer inspection of the scope of practice" (Beauchamp \& Saghai 2012:54)
} 
However, despite the distinction between research and practice through the establishment of two logical, although non-mutually exclusive, domains, the National Commission already gives credit to interventions labeled as "innovation" that we identify as "non-validated practice", as follows:

When a clinician departs in a significant way from standard or accepted practice, the innovation does not, in and of itself, constitute research. The fact that a procedure is "experimental" in the sense of new, untested or different does not automatically place it in the category of research (National Commission, 1979, edited ${ }^{8}$ )

As stated in the Belmont Report, "innovation" is understood as departing significantly from standard accepted practice. However, innovation does not, in itself, constitute research. Hence, the Belmont Report does not introduce a third category for innovation, but considers it as some sort of medical practice because it is designed to benefit the individual patient, as stated above in (P2). This has important practical consequences because considering an innovative intervention as a clinical practice implies that the intervention underlies the general regulations of medical practice and not those of clinical research (Mastroianni, 2006).

Nevertheless, since the innovative intervention does not show sufficient evidence, it cannot be considered validated medical practice, and hence does not fulfill the standard interpretation of condition (P3). In our previous work we identify innovation in the traditional research ethics paradigm (Holzer \& Mastroleo, 2018; Mastroleo \& Holzer, 2018) as nonvalidated practice (Levine 1979, 2008). We believe that this interpretation of the National

\footnotetext{
${ }^{8}$ The unedited complete quotation of the paragraph on innovation in Belmont Report is the following "When a clinician departs in a significant way from standard or accepted practice, the innovation does not, in and of itself, constitute research. The fact that a procedure is 'experimental', in the sense of new, untested or different, does not automatically place it in the category of research. Radically new procedures of this description should, however, be made the object of formal research at an early stage in order to determine whether they are safe and effective. Thus, it is the responsibility of medical practice committees, for example, to insist that a major innovation be incorporated into a formal research project." (National Commission, 1978)
} 
Commission's work is useful because it integrates and connects a recent trend in the research ethics literature that has often adopted this specific meaning of innovation (Brierley and Larcher, 2009; London, 2006; Mastroianni, 2006; Sugarman, 2012; Taylor, 2010).

\subsection{Levine's definition of non-validated practice}

As presented in the previous section, the Belmont Report states that "practice" refers to diagnostic, preventive, or therapeutic interventions designed to enhance the well-being of an individual with reasonable expectations of success. In contrast, "research" is designed to test hypotheses and permit conclusions that generate generalizable knowledge, irrespective of the use of interventions or procedures intended to provide direct health benefit for the individual patient-subject. ${ }^{9}$ However, Levine points out that there is one particular subclass of "medical practice" which he describes as "non-validated practices". Here, he notices that the National Commission refers to non-validated practice in various ways and in different documents by using terms such as "innovative therapies" or "experimental design". In a following step, he argues that the best designation of these terms is "non-validated practice", defining it as follows:

Nonvalidated practices. A class of procedures performed by physicians conforms to the definition of 'practice' to the extent that these procedures are [P2] 'designed solely to enhance the well-being of an individual patient or client.' However, [not P3] they may not have been tested sufficiently often or sufficiently well to meet the standard of having 'a reasonable expectation of success'. (Levine, 1979:22, edited).

\footnotetext{
${ }^{9}$ However, Levine already argues that there are plenty of medical practices including, for example, public health practices or practices for the benefits of others that overlap with the aims of research. In turn, research also takes into consideration the well-being of a research subject to some extent (Levine, 2008).
} 
Comparing this definition with the Belmont Report's definition of validated practice presented above, we note that non-validated practice meets the first two conditions, namely the purpose and scope of interventions (P1) and the design to benefit an individual (P2). However, the definition does not comply with the third condition of 'reasonable expectations of success' (not P3) due to a lack of sufficient evidence of the intervention. Hence, medical practice can be classified as validated or non-validated practice. This is in line with the reality of medical practice where not all interventions used to enhance the well-being of patients are sufficiently validated. Consequently, the term "practice" in traditional research ethics refers to a complex activity whose main aim is to enhance an individual patient's well-being. This implies the level of evidence of the intervention used is not a sufficient condition to determine the type of activity, research or practice. Rather, the defining condition is given by the main aim or intention of the activity. In Levine's more colloquial terms, "it depends upon what you're intending to do" (Levine 2004) whether something is framed as research or practice.

\subsection{Innovative care as new non-validated practice}

In the previous sections, we have introduced and clarified the definitions of research, validated practice and non-validated practice. Moreover, we started this section with a neutral definition of new non-validated practice as the first or recent use of interventions that introduce a significant change, with an insufficient level of safety or efficacy for regular healthcare, and with the main aim to benefit patients (Mastroleo and Holzer 2018). Our definition of new non-validated practice is narrower than Levine's definition of non-validated practice and distinguishes practice between two definitional attributes, validation and novelty (and not only validation, as Levine proposes). Below, we introduce our own classification of 
practice (with slight modifications regarding our framework in Holzer and Mastroleo 2018) based on these two definitional attributes:

\begin{tabular}{|c|c|c|}
\hline Validation & New practice & Long-standing practice \\
\hline Non-validated practice & $\begin{array}{l}\text { New non-validated } \\
\text { practice } \\
\text { (innovation/innovative care) } \\
\text { Examples: Jim Gass' stem } \\
\text { cell interventions, genome } \\
\text { editing therapeutic } \\
\text { interventions, Zhang's } \\
\text { mitochondrial replacement } \\
\text { techniques, genomic } \\
\text { sequencing diagnosis for } \\
\text { rare diseases (Section II). }\end{array}$ & $\begin{array}{l}\text { Long-standing non- } \\
\text { validated validated } \\
\text { practice } \\
\text { Example: routine } \\
\text { episiotomy for vaginal birth } \\
\text { (Carroli and Mignini, 2009) }\end{array}$ \\
\hline Validated practice & $\begin{array}{l}\text { New validated practice } \\
\text { Example: Imatinib for } \\
\text { chronic myeloid leukemia } \\
\text { after FDA approval (Druker, } \\
2009 \text { ) }\end{array}$ & $\begin{array}{l}\text { Long-standing validated } \\
\text { practice } \\
\text { Example: Aspirin for } \\
\text { headaches }\end{array}$ \\
\hline
\end{tabular}

Table 1. Medical practice characterized by validation and novelty 
As we argued in Holzer and Mastroleo (2018), we think that it is of great importance to add the distinction between new and long-standing non-validated practice because both categories imply different real-world problems. By definition, both subtypes of non-validated practice lack a sufficient level of evidence regarding safety or efficacy for regular healthcare use from the point of view of a sound scientific standard. Since new non-validated interventions -or "innovation" as it is referred in the Belmont Report- introduce a significant change, they can be and have been easily confused with research (National Commission 1978, Taylor 2010). This problem has never concerned long-standing non-validated practices. ${ }^{10}$

In our recent work (Holzer and Mastroleo, 2018; Mastroleo and Holzer, 2018), we also analyze the three core elements of our definition of new non-validated practice: novelty ("first or recent use of interventions that introduce a significant change"), validation ("use of interventions with an insufficient level of safety or efficacy for regular healthcare") and practice ("use of interventions with the main aim to benefit patients"). After outlining some general remarks about our definition, we would like to present the results of our previous conceptual analysis.

\subsubsection{General remarks on our conceptual framework}

First, it is useful to distinguish between normative and descriptive concepts in research ethics and to note explicitly that traditional definitions of practice and research -and our definition of new non-validated practice in particular- are normative definitions in the sense that they propose certain conditions to be sufficient to assign an intervention to a certain class of

\footnotetext{
${ }^{10}$ Gracia (2013), one of the most influential scholars in Latin American bioethics (Álvarez-Díaz, 2012, p. 18), has developed an alternative classification of practice that captures a similar distinction in a different way. This gives us independent support to the idea that rethinking the classifications of practice might be a useful effort.
} 
interventions. This categorization determines whether a medical activity ought to be called validated practice, non-validated practice, or research, independently of whether these categories are in fact being used in practice.

The traditional research ethics distinction between validated practice, non-validated practice (innovation), and research is owed to the debate on the conceptual boundaries of practice and research (Levine, 2004). As Beauchamp and Saghai (2012) explicitly state, the National Commission realized that not all accepted practices used in regular healthcare were scientifically sound and validated. After more than 40 years, this is still the case regarding the current practice of some interventions, as for instance, episiotomy, the surgical enlargement of the vaginal orifice by an incision of the perineum to increase the diameter of the vaginal outlet to facilitate the baby's birth. According to the literature, almost $90 \%$ of primiparous women had an episiotomy (Althabe, Belizán, \& Bergel, 2002). This would make routine episiotomy an accepted practice in Latin America (Graham, Carroli, Davies, \& Medves, 2005). However, current sound scientific evidence shows restrictive episiotomy is better than routine episiotomy, generating less overall trauma, less suturing and fewer complications (Carroli \& Mignini, 2009). Thus, routine episiotomy has been for a long time an accepted, but yet non-validated practice, that is, an intervention introduced and maintained with insufficient evidence regarding safety and efficacy for its regular use in healthcare according to our current sound scientific knowledge.

Therefore, it is useful to distinguish between successful and failed instances of new nonvalidated practice (outcome), as well as between responsible and irresponsible instances of new non-validated practice (responsibility). Importantly, the category of innovation itself is morally neutral, meaning that it is independent of the outcomes and the compliance with the principles of responsible innovation. With respect to the latter, responsibility, we believe the definition and concept of innovation should be morally neutral to avoid superficial or even 
flawed justifications and ethical principles, and to allow for reasonable disagreement about what constitutes responsible innovative care (Lipworth et al 2018, Mastroleo and Holzer 2018). Regarding the outcome, our framework departs from London (2006) who considers "improvement" a definitional attribute of "innovation" and distinguishes between "genuine" (successful) and failed innovation. We believe that it is more fruitful to adopt an outcomeneutral definition of innovation, because the ethics of "new non-validated practice" considers the reasonableness and the intention of agents, which cannot be reduced to the success or failure of an intervention. Indeed, a failed new non-validated practice may be also a genuine and responsible new non-validated practice if it follows the appropriate ethical principles.

That way, the success or failure of an intervention is distinct from the evaluation of the conditions of its responsible use. This is analogous to the responsible evaluation of the benefit-harm profile of an intervention, as the benefit-harm profiles pose a judgment ex ante (foreseeable or not foreseeable) instead of ex post (realized or not realized). We argue that the core concern of defining innovation as new non-validated practice is the aim of an activity, namely to enhance the well-being of patients or the intention to use that intervention to end or alleviate current suffering of a patient. Neither realized success, nor failure, poses a necessary condition for the responsible use of new non-validated practice. As we will show in section $\mathrm{V}$, responsible new non-validated practice is assessed not by its success or failure, but by the ethical principles of responsible new non-validated practice.

\subsubsection{Novelty}

We stipulate that the attribute "novelty" or "new" refers to the recent or first use of an intervention that introduces a significant change in practice. Furthermore, we use the term 
"long-standing" in Table 1 as the logical opposite to "new" in the sense that we refer to the recent or first use of an intervention that introduces a significant change.

Here, it is useful to analyze the term "significant change" and differentiate it from "mere variation" or non-significant change (ACOG, 2015, p. 5; London, 2006, p. 31) to avoid the inclusion of meaningless changes in practice under the label of "new" practice. This would be important in view of the principles for responsible new non-validated practice, in particular to allow effective regulation and practicality. In most cases, changing the color of surgery gloves from blue to indigo would probably not be considered a significant change. However, a change from latex to nitrile gloves could be a significant change, and hence a new nonvalidated practice, given that latex allergies are a concern in certain circumstances. More formally, the criterion to distinguish between significant change and mere variation is that a change is significant if it entails a relevant modification in the benefit-harm profile of the intervention, given a specified context (London, 2006, p. 31).

\subsubsection{Validation}

Due to reasons of stipulating with the scope of this chapter, we cannot dwell on what Beauchamp and Saghai call the "epistemic problem" in the clinical context, which refers to the conditions under which medical interventions are sufficiently validated. However, following Beauchamp and Saghai (2012:49-50), we can note the following three points. First, a significant number of insufficiently validated interventions in medical practice fall short of the validation standards set by randomized clinical trials. Second, not all members of the scientific community accept the view that the validation of an intervention is obtained solely by randomized clinical trials (RCTs). Thus, there is a strong disagreement among researchers regarding the different methods or research activities of validation at stake. In fact, "RCTs 
have never monopolized medical knowledge production" (Bothwell et al., 2016). Moreover, there seem to be good arguments not to consider randomized clinical trials as a universal gold standard, but rather to adopt a case-by-case approach applying different research methods and methodologies to untested and new interventions when necessary (Cartwright 2007, Diaz \& Neuhauser 2005). Third, the fact that an intervention is accepted in practice does not necessary provide a reason to believe that the safety and efficacy of that intervention are supported by sufficient evidence (e.g. routine episiotomy for vaginal birth).

Thus, instead of offering an epistemically unwavering account for the evidence of an unproven intervention, we interpret the Belmont Report's criterion (P3) of "reasonable expectations of success" as an epistemic standard relative to a specified body of information and a specified range of reasons. As we will argue, a certain level of evidence may not be sufficient to call a medical activity validated practice. However, the level of evidence may be enough to consider the activity as "new non-validated practice".

In the case of new non-validated interventions, the limited clinical and/or preclinical evidence of effectiveness and safety may not amount to the full validation of an intervention relative to the appropriate epistemic standard. In these circumstances, physicians have good reasons to restrict the use of a new non-validated intervention (e.g. cord blood transplant) to few individual patients. This means the intervention should not immediately applied at a population level (i.e. all children with Fanconi's anemia) in regular healthcare due to lacking "reasonable expectations of success". However, even if the probabilities of success are low or uncertain regarding the use in regular healthcare of a new non-validated practice, it may still show a minimum level of evidence to be a reasonable option in a limited number of cases in which patients do not have medical alternatives or what we call "exceptional circumstances". That is the case because even if an intervention has not been tested sufficiently often or sufficiently well, this does not imply that the intervention has no evidence at all (Levine, 
1979:22). Thus, it seems reasonable to distinguish between (i) a minimum level of evidence necessary to be a reasonable option for individual patients in exceptional circumstances and (ii) the criterion of "reasonable expectations of success" as it is used in Belmont Report and Levine's definition of non-validated practice, which we associated with validated practices relative to an appropriate epistemic standard for use in regular healthcare of general population.

Nevertheless, even if an intervention lacks sufficient evidence to reach the appropriate standard of validated medical practice for regular healthcare, to be scientifically sound an intervention has to reach a minimum level of evidence to be a reasonable option even in exceptional circumstances. Furthermore, without a minimum level of evidence in support of the efficacy and safety of an intervention, it would be futile or irrational for physicians to prescribe and for individuals to undergo the intervention as a last chance. This explains why the ISCCR Guidelines for stem cell research and clinical translation demand for clinical innovation a sound scientific rationale and justification given the lack of alternatives for the patient (scientific validity) (ISCCR, 2016, recommendation 3.4).

\subsubsection{Intention}

Finally, perhaps the most important component of our definition of clinical innovation is that new and non-validated interventions are used as medical practice. This means that the intention or main aim of innovation is (P2) the "well-being of the patient" and not (R2) the generation of or contribution to "generalizable [scientific] knowledge" as in clinical research (National Commission, 1979, Levine, 1979).

There are important real-world implications of defining new non-validated practice as a type of medical practice related to intentionality, benefit-harm evaluation and responsibility. First, 
our definition of "new non-validated practice" does not state that new non-validated interventions fall into a "grey zone" between research and practice (King 2002). Following the traditional definition of Levine and the Belmont Report, we define new non-validated practice as part of medical practice and not as research. Thus, clinical innovation refers to the use of an intervention that falls under medical practice, understanding "practice" as a practical context were physicians apply preventive, therapeutical or diagnostic means with the main aim of benefiting patients. The "grey zone" is overcome by the agents response to the basic question "what you're intending to do" (Levine 2004). Following the basic intuition of traditional research ethics, our framework explicitly highlights that the intention of an intervention is something to be considered to determine its responsibility regime and its ethical permissibility.

Second, one important aspect of defining new non-validated practice as an activity with the main aim to benefit individual patients concerns the benefit-harm analysis. Interventions considered as new non-validated practice should be subject to a benefit-harm profile evaluation according to the standards of medical practice, not research (Levine, 1979:22). According to Weijer and Miller (2004) and as stated by King and Churchill (2008), the benefit-harm analysis in clinical research is considerably distinct from the evaluation in medical practice. While therapeutic risks as well as non-therapeutic risks (that are not directly associated with therapeutic procedures) occur in the context of clinical research, all risks directly relate to the individual in the case of medical practice. In the case of research, nontherapeutic risks that occur in the context of non-therapeutic procedures and that are unrelated to the intended improvement of a patients' well-being procedures are balanced with potential therapeutic benefits to the research subjects, and ought to be in reasonable relation to the knowledge gain and social benefit to society (Weijer and Miller, 2004, Emanuel et al., 2000). Hence, benefits to society are an additional factor in the assessment of research and 
the threshold for potential benefits to individuals might be considerably lower than in the case of medical practice (King and Churchill, 2008).

When we apply the aforementioned considerations on the risk-benefit analysis to the concept of new non-validated practice, we argue that the ethical evaluation of a benefit-harm profile should be in accordance with the ethical evaluation of medical practice. If a new nonvalidated intervention is the only reasonable intervention for diseases with potentially lifethreatening or strongly life-impairing characteristics primarily designed to enhance the wellbeing of patients, high risks can be reasonably accepted.

Nevertheless, risks that occur in the setting of clinical innovation ought to be in accordance with general guiding frameworks about risks. For instance, King and Churchill (2008) explain that there are some risks that can never be justified, and all significant risks of serious harms must have unassailable justification. Risks of harm should always be minimized.

\section{Justification: What is the ethical justification of innovation as new non-validated practice?}

In the previous section we defined new non-validated practice as the use of new, interventions that are insufficiently validated for regular healthcare, but show a sufficient minimum of evidence to be considered reasonable, and aim to benefit individual participants in exceptional circumstances. In this section, our aim is to offer an ethical justification for new non-validate practice. This justification is intended to prove the ethical permissibility of new non-validated practice -at least within the limits of exceptional circumstances- in order to attenuate debunkers who sustain that insufficiently validated interventions should only be accessed by the means and under the regulations of research. 
Emanuel's reformulation of the principle for the use unproven interventions in the Declaration of Helsinki of the WMA (2013, paragraph 37) can be construed as an objection to the traditional definition of non-validated practice in general and our definition of new non-validated practice in particular:

6. Research of Unproven, "Last Ditch" Treatments: In the treatment of a patient, where proven interventions do not exist or have been ineffective, the physician, after seeking expert advice, with informed consent from the patient or a legally authorized representative, may use an unproven intervention to promote the patient's health or well-being, but only if it is undertaken as a research study designed to evaluate its safety and efficacy. Repeated uses of an unproven intervention can only be justified as part of a research study that fulfils all the protections in this Declaration. (Emanuel, 2013, supplementary appendix)

One possible interpretation of Emanuel's reformulation of the non-validated practice principle is that it eliminates the traditional tripartite distinction in research ethics of validated practice, non-validated practice, and research. Only validated practice and research are ethically permissible categories. Non-validated practice is ethically forbidden, even for "last ditch" treatments, such as interventions used for the benefit of patients with unmet health needs and no reasonable alternatives. Emanuel's reformulation of the principle for the use of unproven interventions is an intellectual exercise and has never been incorporated into the Declaration of Helsinki. One limitation of this exercise is that Emanuel's principle has no justification in itself. Why should insufficiently validated interventions only be undertaken in the context of a research study? One plausible reason to justify his principle is the shared concern in the literature that the unrestricted facilitation of new non-validated practice outside sound scientific research may endanger the generation of generalizable scientific knowledge, which could entail negative consequences for public health (ACOG Committee on Ethics, 
2015; Little \& Wickremsinhe, 2017; Rosemann, Bortz, \& Vasen, 2018). We have called this concern "epistemic crowding out of sound research" in our previous work (Mastroleo and Holzer, 2018).

It is commonly argued that unrestricted new non-validated practices can lead to less recruitment of patients in research trials, especially when patients have the incentive to receive their preferred intervention in one hundred percent of the cases (rather than, for example, having only a fifty percent chance of receiving it in randomized controlled trials) (ACOG Committee on Ethics, 2015, pp. 3-4; Daniels \& Sabin, 1997). Unregulated promotion and advertising may foster this tendency even more (ACOG Committee on Ethics, 2015, pp. 3-4).

If sound scientific evidence to validate interventions for the regular healthcare use could not be attained outside multi-phase randomized controlled trials or other sound scientific research designs, it would be reasonable to accept and limit new non-validated practice. This is precisely the case when we foresee that the uncoordinated and unlimited aggregation of the individual use of new non-validated practice seriously risks a "crowding out" of sound scientific research with untoward consequences for public health, as the recent discussion on the "right to try legislation" exemplifies (Dresser 2016; Joffe and Lynch 2018). Hence, we believe that potential epistemic crowding out effects are important enough to regulate and limit what is usually referred to as "innovation" or "new non-validated practice" (regarding our particular interpretation of it).

However, this concern is not enough to ethically forbid non-validated practice, as Emanuel's principle states. Social expediency should not be confused with what is ethically appropriate. Here, we hold the plausible position that epistemic crowding out of sound research is not a necessary consequence of new non-validated practice. For instance, ethics frameworks, such 
as the ISSCR guidelines (2016, recommendation 3.4), address this issue by stating that new non-validated practice must remain the exceptional case to avoid undermining public trust, exploiting patients' hope and delaying sound research. New non-validated interventions should be used in a very small number of patients outside of research with an obligation to move to sound research in a timely manner after experience with, at most, a few patients. This latter obligation is described in the literature as the "commitment to contribute to generalizable knowledge" (ISSCR, 2016; Sugarman, 2012). In turn, this ethical requirement can be seen as a form of bridging the gap between practice (intention to enhance patients' well-being) and research (intention to contribute to generalizable knowledge).

Moreover, the ethical requirement of the "commitment to contribute to generalizable knowledge" is also present in the traditional view in research ethics. Both, the Belmont Report and the Declaration of Helsinki, acknowledge this rationale as one of the core ethical requirements of the responsible use of new non-validated practice. ${ }^{11}$ However, as the literature shows, there are contextual obstacles to support this ethical requirement in realworld situations, such as the lack of research infrastructures in new fields of medicine, the lack of specific oversight structures for new non-validated practice, the prohibition of national research funding in certain clinical areas (e.g. embryo research), etc. (ACOG, 2015, pp. 4-5; Rosemann et al., 2018; Taylor, 2010). Hence, crowding out of sound research is not generated by one single use of a new non-validated intervention in isolation, but by the repeated use of new non-validated interventions in an unregulated context.

\footnotetext{
11 “[...] [Unproven] intervention should subsequently be made the object of research, designed to evaluate its safety and efficacy. In all cases, new information must be recorded and, where appropriate, made publicly available" (WMA, 2013, para. 37) , and "Radically new procedures of this description should, however, be made the object of formal research at an early stage in order to determine whether they are safe and effective. Thus, it is the responsibility of medical practice committees, for example, to insist that a major innovation be incorporated into a formal research project" (National Commission, 1978).
} 


\section{Regulation: What are the basic ethical principles of responsible innovation as new non-validated practice?}

In the previous section we defended the permissibility of new no-validated practice in exceptional situations against the objection of "epistemic crowding out". Now, we are going to specify the principles of "responsible innovation" understood as "new non-validated practice". As we have argued in the analysis of the definition of new non-validated practice, the principles of this complex activity set the standards for evaluating the conduct of responsible agents. We will put forward in the last section that this set of principles is useful to distinguish between serious and responsible doctors from dishonest and unscrupulous ones.

The Declaration of Helsinki in 2000 (WMA, 2000, paragraph 30) states that given the patient gives informed consent, physicians must be free in choice to apply unproven or new preventive, diagnostic and therapeutic measures if they are considered potentially life-saving, re-establish health or alleviating suffering for patients without reasonable alternatives.

This principle has already been acknowledged in the first version of the declaration (WMA, 1964) under the section "clinical research combined with professional care". Here, the Declaration states that "[I]n the treatment of the sick person the doctor must be free to use a new therapeutic measure if in his judgment it offers hope of saving life, re-establishing health, or alleviating suffering” (WMA 1964, paragraph 1, section II). This applies to all cases in which proven preventive, diagnostic and therapeutic methods do not exist, are rare or not acceptable. It also includes conditions for the compassionate use of drugs. For instance, a physician may decide that it is reasonable to offer an individual patient an unproven intervention outside clinical trials when she is not eligible for a research study. Likewise, physicians may conclude that an individual patient can profit from new non-validated 
interventions, such as those ones that occur in the context of individualized diagnostics and therapies, and which cannot be currently tested under a rigid and methodologically sound clinical trial.

Importantly, next to assigning responsibilities to physicians, the Declaration of Helsinki gives credit to individual patients' health conditions that go along with substantial suffering. Thus, the application of potentially risky innovative interventions is not justified if the patient has no substantial health need to undergo the new and unproven intervention. This use of nonvalidated interventions in medical practice has sometimes been identified with the category of "therapeutic research" (Levine 1979). However, Levine has systematically criticized “therapeutic research" as a conceptually problematic category (Levine 1979:23, 1999, 2008) and states that "non-validated practice" replaces this category in the most developed reports of the National Commission (Levine 1979:23).

The ethical principle in the Declaration of Helsinki (WMA, 2000, paragraph 30) for the use of "last-ditch" unproven interventions, applied after a careful assessment by physicians seeking expert advice, has remained with minor changes in the revised versions of the Declaration in 2008 (WMA, 2008, paragraph 35) and in 2013 (WMA, 2013, paragraph 37). Following the latest version, this has been labeled as the paragraph for the appropriate use of "unproven interventions in clinical practice". Regarding this account, innovation as new non validated practice must respect certain conditions to be considered as a responsible activity:

37. In the treatment of [1] an individual patient, where proven interventions do not exist or other known interventions have been ineffective, the physician, [2, 3] after seeking expert advice, [4] with informed consent from the patient or a legally authorised representative, may use an unproven intervention if [5] in the physician's judgment it offers hope of saving life, re-establishing health or alleviating suffering. 
[6] This intervention should subsequently be made the object of research, designed to evaluate its safety and efficacy. [7] In all cases, new information must be recorded and, where appropriate, made publicly available. (WMA, 2013, paragraph 37, edited).

The Declaration of Helsinki reveals certain core principles that are also recognized by the ISSCR (2016, recommendation 3.4.1). The principle of "provision of innovative care" guides physicians when using new non-validated practice, which ought to comply with the following ethical requirements:

1. Exhausting circumstances and limited number of patients,

2. Scientific validity,

3. Independent review,

4. Informed consent,

5. Priority of patient well-being,

6. Commitment to contribute to generalizable knowledge through research,

7. Publication of results.

Some of the principles show similar labels compared to the ones commonly referred to in research ethics (e.g. scientific validity, independent review, informed consent, e.g.).

However, their content and application may differ substantially from research since these are principles of non-validated practice intended to benefit patients. So we should be careful of evaluating new non-validated practice without mistaking it for research, as pointed out by Taylor (2010). This list of ethical requirements provides an initial ethical framework to balance the aim to attain generalizable knowledge through research with the aim to attend the needs of patients with no reasonable alternatives. 
Moreover, recognizing appropriate limits to new non-validated practice strengthens our argument that new and insufficiently validated interventions should not always be subject to research, which goes hand in hand with restrictive regulations, precisely in cases in which patients lack reasonable medical alternatives. We call this argument the "argument of lacking reasonable alternatives". This argument sustains that physicians can and maybe sometimes should use unproven interventions in exceptional situations within the context of medical practice.

As stated by Sugarman (2012), the lack of reasonable medical alternatives for an individual goes along with a changed evaluation of the risk-benefit profile of an unproven intervention. The mere fact that individuals cannot access any alternative treatment can make even a low expectation of success of the unproven therapy ex ante a rational and acceptable choice for them, given that the intervention reaches a minimum threshold of sound evidence. Surely, we should point to the responsibilities physician have in this context. The evaluation of the reasonability and acceptability of an unproven intervention is part of a cautious balancing and judging process by the physician. It might be ethically wrong for a physician to make a patient undergo a non-validated intervention outside the context of clinical research in the case of available clinical trials or validated medical alternatives.

\section{Conclusion: What is the importance of responsible innovation as new non-validated practice in Latin America?}

So far, this chapter presented a conceptual framework of "new non-validated practice" to interpret the meaning of the terms "innovation" and "innovative care" within the larger category of medical practice, and not research. We intended to support our approach by arguing that this classification is necessary from an epistemic and ethical stance. In particular, 
it is ethically necessary and reasonable to consider new non-validated practice as medical practice and not as research in order to align it with the urgent health needs of patients with no reasonable medical alternatives. If our previous arguments are sound, new non-validated practice in the appropriate circumstances has the potential to benefit individual patients and society. Hence, we should be cautious about treating new non-validated practice as an inferior kind of activity in comparison with research. As Taylor reminds us:

That innovative therapy can be, and continues to be, so positively transformative in the right circumstances, ought to make us cautious, I think, about treating it as a presumptively flawed and inferior activity that requires the corrective guidance of the research paradigm. Each is legitimate in a certain sphere; each has different goals; and, as I shall argue, each has distinct oversight needs. (Taylor, 2010:286)

This position would most probably have a substantive impact on the norms and practices of regulating new non-validated interventions in the clinical context.

In this last section, we want to put emphasis on the importance to develop a valid concept of innovation as new non-validated practice in the light of new emerging therapies and diagnostics and its regulations and applications in the Latin American context. All of the scientific and social promises that originate from significant changes in treatments and diagnostic tools, such as the presented cases of stem cell interventions, gene editing, mitochondrial transfer technologies, or genome sequencing, nourish hope within research. This discussion goes along with the hope to find solutions for patients with yet lacking alternatives for their health conditions, but should take into account its potential benefits as well as its risks. In our view, our case examples clearly fall under the neutral concept of new non-validated practice due to their novelty, their insufficient validation, and their alleged main aim to foster an individual patient's well-being. However, as we will argue, not all cases 
of non-validated practice are cases of responsible innovation. Now, let us have a look at the potential impact and use of our framework for individual patients, ethics committees, and Latin American societies.

\subsection{Recommendations for doctors, individual patients and surrogates}

In our view, innovation as new non-validated practice is a reasonable possibility given to patients with no or no reasonable medical alternatives, when applied within the limits of responsible innovation, as outlined in the previous section.

One important concern by individual patients is to distinguish between responsible doctors and scientists from pretenders, charlatans, and dishonest health professionals in general. Scientific assessment of new interventions may be out of reach for most patients. This asymmetric situation regarding the level of epistemic knowledge is analogous to other asymmetric epistemic situations in our everyday lives, such as the legal context. One possibility for patients or their representatives would be to appoint their trusted doctors to function as advisors, as we usually do with trusted lawyers to guide us through legal transactions.

However, although a sound epistemic evaluation of new scientific interventions may be out of reach to most of us, the ethical character of institutions and doctors may be yet accessible. Principles of "responsible innovation" understood as new non-validated practice can be used to do a prudential evaluation of a particular doctor who offers a new non-validated intervention in a particular institution. Our practical hypothesis is that when an agent complies with the ethical principles of responsible treatment, she is more likely to be committed to scientifically sound actives than to charlatanry. In this regard, patients or their surrogates may be indeed capable to notice whether a praised intervention is rather futile or scientifically sound and in line with the promise to enhance their individual well-being. 
For instance, one good proxy for responsible innovation is the publication of results in the scientific literature. Although this is not always the case, once doctors have already published results of previous uses of a new non-validated practice in well-known peer-reviewed scientific journals, it seems more likely that these interventions are scientifically sound and its overall use responsible. As Jim Gass recalls, when he asked for evidence regarding his treatments, the treating physicians could not provide reliable scientific information about the treatment's evidence, but anecdotes and testimonies of patients getting "dramatically better" (Kolata 2016). As Mr. Gass notes, the websites of the respective clinics often provided data that had previously been published in vanity journals. When asked by Kolata (2016) what he would like others to learn from his experience, Mr. Gass said "don't trust anecdotes".

As the case of Jim Gass shows, we can generally notice that only some of the Latin American examples we choose follow what we call responsible new non-validated practice. This claim is supported by various authors, most notably by Rosemann (2013) and Palacios-Gonzales and Medina-Arellano (2017a, 2017b) who lament that vague regulations and loop holes in health law allow scientists to apply innovative therapies to patients outside the limits of responsible innovation as new non-validated practice. New non-validated practice can indeed be conducted under the false pretenses of beneficial purposes even though the intervention may lack transparency or a minimum level of sound evidence and scientific validity (see Rosemann 2013). These concerns and lessons from stem cell tourism can be transferred to other contexts of new non-validated practices (Charo 2016).

As the case of Jim Gass further shows, a reasonable analysis of benefits, risks, scientific validity, and the prospect of the applied stem cell therapies -as e.g. demanded by the ISSCR guidelines (2016)- has not been done within the limits of a sound external evaluation procedure. Also, it remains unclear whether Jim Gass' health need and desperate health state were reasons urgent enough to undergo unproven stem cell therapies. In other words, we may 
wonder if his therapies could ever be considered legitimate in the sense that he had no reasonable medical alternatives and the suffering was strong enough to justify the application of non-validated interventions outside a sound research activity. Most probably, one may suspect that the involved physicians were attracted by the prospect to apply their novel therapies with no regulatory hurdles and clinics in countries with few regulations may have speculated to gain advantage from these so-called stem cell tourists. As shown by anecdotal evidence, negligence or complicity of political authorities cannot be ruled out.

However, following the principles of responsible innovation as new non-validated practice offers a good way to assure that doctors and scientists do not take advantage of the desperate situation of patients to test innovative interventions, but act in the interest of the patient to enhance or re-establish her well-being. Hence, these principles may offer a useful tool to educate doctors and scientists regarding their professional ethos and integrity.

\subsection{Recommendations for ethics committees}

In light of our analysis, we think that ethics committees can make use of our framework of new non-validated practice to deliberate on how to categorize and link different activities to different medical contexts (validated practice, non-validated practice and research). Generally speaking, we believe that a public deliberation would show respect for patients and fosters public trust. Also, scientists' or doctors' behavior could be evaluated more easily by following the principles of "responsible innovation" (ISSCR 2016, Sugarman 2012) as new non-validated practice.

We furthermore think that it is very important to put emphasis on the fact that ethics committees need to address new non-validated interventions outside clinical trials or other 
research activities in a sufficient and responsible way. These considerations go along with Taylor's (2010) notion of the different real-world contexts of standard care, clinical innovation and research or analogously, with the standard distinction between validated practice, non-validated practice and research. According to Taylor, these contexts are not opposed, but interact in many and different biomedical fields.

"Innovative therapy [that is new non-validated practice] develops in diverse ways. [...] With this model, innovative therapies are suggested by understanding where current therapies fail, and combining that knowledge with hypotheses about how changes in somewhat-known compounds might affect their action on other diseases." (Taylor, 2010:287, edited)

As Taylor explains, research and "innovative therapy" (interpreted here as new non-validated practice) are always somewhat interrelated practices that occur in different medical fields. Most notably, the fields of new therapies and diagnostics in biomedicine make the category of "innovation" even more salient. As we have previously shown, undergoing new and insufficiently tested interventions outside clinical trials or other sound research activities can be ethically justified in cases in which individuals lack reasonable medical alternatives or when appropriate trials cannot be made available.

\subsection{Recommendations for society}

Society as a whole can use the principles of responsible innovation to revise current regulations and shape new ones specifically targeted to new non-validated practices whose use does not fall under a sound research activity. Still, there are innovative diagnostics uses, 
such as genome sequencing for rare diseases, that clearly relate to the aim to foster a patient's well-being, but are regulated by the standards of research. Also, as argued by PalaciosGonzales and Medina-Arellano (2017a), reproductive technologies, such as MRTs may be forbidden depending on the specific reading of Mexico's Health Law that addresses research. However, in our view, it would be especially useful to address the ethical and epistemic peculiarities of new non-validated practice in separate laws and regulations. As we have argued, the category itself implies a different ethical analysis compared to sound research and validated practice. In this regard, our framework and the principles for the responsible implementation of non-validated practice are very important to guide the public discussion and the deliberative process.

Regarding this deliberative process, there are several issues at stake that societies have to face and to balance carefully. First, there is the obvious demand by individual patients to act as autonomous and rational agents in their interest to foster their health within the limits of "responsible innovation" understood as new non-validated practice. Outside these limits, the application of innovative interventions would not be ethical, and in most cases, not even rational for the individual.

Second, public health demands, however, that those new and non-validated interventions have to be tested in a way that they yield social value for future patients. This means that new and yet unproven interventions must undergo the most rigorous epistemic testing for which randomized controlled trials still serve as a gold standard in many cases. The Belmont Report (1979), the Declaration of Helsinki (2013, paragraph 37) and the ISSCR guidelines (2016) incorporate this rationale by stating that the application of innovative interventions in particular cases with therapeutic, preventive, or diagnostic purposes must be made object of formal research -after the exceptional use as medical practice for an individual patient- to further attain a sound epistemic evaluation of the intervention. If regulatory frameworks 
ignore this guiding principle, there is the danger of an 'epistemic crowding out' effect that hinders social value for society to the benefit of individuals with urgent health needs who access the interventions outside clinical trials or other sound research activity. Even patients who want to access new non-validated practice, such as expanded access programs (also called "compassionate use"), could benefit from sound statistical analyses of such interventions in sound research (Joffe and Lynch 2018). Here, we also want to point to the potentially important role of drug regulatory agencies to balance interests of individual patients, future patients, scientists, health professionals, and companies (Joffe and Lynch 2018).

Third, as argued mostly by scientists (see Luna and Salles 2010), offering a fruitful environment for the application of research and new non-validated practice, especially in the field of stem cell therapies, gene editing, and novel reproductive technology, can have very positive scientific and economic effects in Latin American countries. According to Harmon and Laurie (2008), Argentine scientists look at stem cell research as a promising new opportunity for the country to achieve international recognition and serve as a regional leader (see also Luna and Salles 2010). However, society must be cautious and not let dubious and profit-driven clinics benefit from regulatory loopholes and desperate medical tourists. Therefore, guidelines and regulations have to be developed and/or improved to prevent such dubious cases and to ensure a responsible application of new biomedical interventions.

Last, there remains the big question about conservative views on innovative methods and technologies in the biomedical field, especially as far as embryonic stem cell interventions are concerned. Here, we do not argue that society would need to ban the Catholic Church or other religious groups from public deliberation -if they respect the principles of reasonable democratic argumentation-, as it represents a valuable and common view among citizens and offers important 'social capital' for society (Habermas and Ratzinger 2008). Nevertheless, 
Latin American societies should allow a reasonable pluralism concerning comprehensive doctrines and public opinions on new and yet unproven biomedical technologies. In particular, rights of less powerful individuals, groups and underrepresented voices, and patients ought to have a secure and protected place in the public debate. 


\section{References}

ACOG Committee on Ethics. (2015). ACOG Committee Opinion No. 352: Innovative practice: ethical guidelines. Obstetrics and Gynecology, 108(6), 1589-1595.

Administración Nacional de Medicamentos, Alimentos y Tecnología Médica (ANMAT) (2010). Disposición 6677/2010 “Régimen de Buena Práctica Clínica para Estudios de Farmacología Clínica", http://www.anmat.gov.ar/comunicados/dispo_6677-10.pdf Althabe, F., Belizán, J. M., \& Bergel, E. (2002). Episiotomy rates in primiparous women in Latin America: hospital based descriptive study. Bmj, 324(7343), 945-946.

Álvarez-Díaz, J. A. (2012). Latin American bioethics or bioethics in Latin America? Revista Latinoamericana de Bioética, 12(1), 10-27.

Beauchamp, T. L., \& Saghai, Y. (2012). The historical foundations of the research-practice distinction in bioethics. Theoretical Medicine and Bioethics, 33(1), 45-56. https://doi.org/10.1007/s11017-011-9207-8

Brierley, J., \& Larcher, V. (2009). Compassionate and innovative treatments in children: a proposal for an ethical framework. Archives of Disease in Childhood, 94(9), 651-654. https://doi.org/10.1136/adc.2008.155317

Cámara de Diputados del H. Congreso de la Unión, Reglamento de la ley general de salud en materia de investigación para la salud (1987). Accesible at http://www.hcg.udg.mx/PAGs/Sec_Transparencia/PDFs_Transparencia/II_D_RF_3.pdf [accessed April 02, 2018]

Carroli, G., \& Mignini, L. (2009). Episiotomy for vaginal birth. In Cochrane Database of Systematic Reviews. John Wiley \& Sons, Ltd. Retrieved from http://onlinelibrary.wiley.com/doi/10.1002/14651858.CD000081.pub2/abstract 
Chan, S., \& Arellano, M. M. (2016). Genome editing and international regulatory challenges: lessons from Mexico. Ethics, Medicine and Public Health, 2(3), 426-434.

Charo, R. A. (2016). On the Road (to a Cure?)--Stem-Cell Tourism and Lessons for Gene Editing. The New England Journal of Medicine, 374(10), 901-903. https://doi.org/10.1056/NEJMp1600891

Committee on Bioethics. (2013). Committee on Genetics, and the American College of Medical Genetics and Genomics Social, Ethical, and Legal Issues Committee: Ethical and policy issues in genetic testing and screening of children. Pediatrics, 131(3), 620-622.

Congregation for the Doctrine of the Faith (1987). Donum Vitae. Rome: The Vatican.

Congregation for the Doctrine of the Faith (2008). Dignitas Personae. Rome: The Vatican, available at http://www.vatican.va/roman_curia/congregations/cfaith/documents/rc_con_cfaith_doc_2008 1208 dignitas-personae_en.html [accessed April 02, 2018]

Córdoba, M., Rodriguez-Quiroga, S. A., Vega, P. A., Salinas, V., Perez-Maturo, J., Amartino, H., ... Kauffman, M. A. (2018). Whole exome sequencing in neurogenetic odysseys: An effective, cost- and time-saving diagnostic approach. PLOS ONE, 13(2), e0191228. https://doi.org/10.1371/journal.pone.0191228

Daniels, N., \& Sabin, J. (1997). Limits to Health Care: Fair Procedures, Democratic Deliberation, and the Legitimacy Problem for Insurers. Philosophy \& Public Affairs, 26(4), 303-350. https://doi.org/10.1111/j.1088-4963.1997.tb00082.x

Diaz, M., \& Neuhauser, D. (2005). Pasteur and parachutes: when statistical process control is better than a randomized controlled trial. BMJ Quality \& Safety, 14(2), 140-143. 
Emanuel, E. J. (2013). Reconsidering the Declaration of Helsinki. The Lancet, 381(9877), 1532-1533. https://doi.org/10.1016/S0140-6736(13)60970-8

Gracia, D. (2013). Práctica clínica e investigación clínica. In R. Dal-Ré, X. Carné, \& D. Gracia (Eds.), Luces y sombras en la investigación clínica (pp. 39-55). Madrid: Triacastela.

Graham, I. D., Carroli, G., Davies, C., \& Medves, J. M. (2005). Episiotomy rates around the world: an update. Birth, 32(3), 219-223.

Habermas, Jürgen, and Joseph Ratzinger. Dialektik der Säkularisierung. Blätter für deutsche und internationale Politik4, no. 2008 (2008): 33-46.

Harmon, S. H. (2008). Emerging technologies and developing countries: Stem cell research regulation and Argentina. Developing World Bioethics, 8(2), 138-150.

Harmon, S., Laurie, G. (2008). The Regulation of Human Tissue and Regenerative Medicine in Argentina: Making Experience Work. Arts and Humanities Research Council, Policy Brief 4. Buenos Aires: Ministry of Science, Technology and Productive Innovation.

Holzer, F. S., \& Mastroleo, I. D. (2018). Ethical Aspects of Precision Medicine: An Introduction to the Ethics and Concept of Clinical Innovation. In H.-P. Deigner \& M. Kohl (Eds.), Precision Medicine: Tools and Quantitative Approaches (pp. 1-19). London: Academic Press-Elsevier. https://doi.org/10.1016/B978-0-12-805364-5.00001-9 International Society for Stem Cell Research (ISSCR). (2016, May 12). Guidelines for Stem Cell Research and Clinical Translation. Retrieved from http://www.isscr.org/docs/defaultsource/guidelines/isscr-guidelines-for-stem-cell-research-and-clinicaltranslation.pdf?sfvrsn=2 
Joffe, S., \& Fernandez Lynch, H. (2018). Federal Right-to-Try Legislation — Threatening the FDA's Public Health Mission. New England Journal of Medicine, 378(8), 695-697. https://doi.org/10.1056/NEJMp1714054

Kaufmann, M. (2013), "Jaque a las enfermedades mitocondriales" http://www.conicet.gov.ar/jaque-a-las-enfermedades-mitocondriales/

Kaufmann, M., Turjanski, A. (2015). Científicos argentinos hallan un gen clave relacionado al autismo, http://www.clarin.com/sociedad/Cientificos-argentinos-hallan-relacionadoautismo_0_1334867289.html

Kolata, G., 2016. A Cautionary Tale for 'Stem Cell Tourism'. New York Times Article published June 22 2016, available at https://www.nytimes.com/2016/06/23/health/acautionary-tale-of-stem-cell-tourism.html?_r=1 [accessed April 17 2017]

Levine, R. J. (1979). Clarifying the concepts of research ethics. Hastings Center Report, 9(3), $21-26$.

Levine, R. J. (1999). The need to revise the Declaration of Helsinki. The New England Journal of Medicine, 341(7), 531-534. https://doi.org/10.1056/NEJM199908123410713

Levine, R. J. (2004, May 14). Robert Levine. Oral History of the Belmont Report and the National Commission for the Protection of Human Subjects of Biomedical and Behavioral Research. Retrieved from https://www.hhs.gov/ohrp/education-and-outreach/luminarieslecture-series/belmont-report-25th-anniversary-interview-rlevine/index.html Levine, R. J. (2008). The Nature, Scope, and Justification of Clinical Research. In E. J. Emanuel, C. Grady, R. A. Crouch, R. K. Lie, F. Miller, \& D. Wendler (Eds.), The Oxford Textbook of Clinical Research Ethics (pp. 211-221). Oxford University Press. 
Ley de Bioseguridad de Organismus Genéticamente Modificados (2005). Article 3, XX, accessible at https://mexico.justia.com/federales/leyes/ley-de-bioseguridad-de-organismosgeneticamente-modificados/titulo-primero/capitulo-i/ [accessed April 02, 2018]

Little, M. O., \& Wickremsinhe, M. N. (2017). Research with pregnant women: a call to action. Reproductive Health, 14(3), 156. https://doi.org/10.1186/s12978-017-0419-x

Lipworth, W., Stewart, C., \& Kerridge, I. (2018). The Need for Beneficence and Prudence in Clinical Innovation with Autologous Stem Cells. Perspectives in Biology and Medicine, 61(1), 90-105. https://doi.org/10.1353/pbm.2018.0029

London, A. J. (2006). Cutting surgical practice at the joints: Individuating and assessing surgical procedures. In A. M. Rietsma \& J. D. Moreno (Eds.), Ethical Guidelines for Innovative Surgery (pp. 19-52). Hagerstown, MD: University Publishing Group.

Luna, F., \& Salles, A. (2010). On moral incoherence and hidden battles: stem cell research in Argentina. Developing world bioethics, 10(3), 120-128.

Luna, F. (2018). From the Middle Ages to the 21st Century. Abortion, Assisted Reproduction Technologies and LGBT Rights in Argentina. Canadian Journal of Bioethics / Revue Canadienne de Bioéthique, 1(2), 26-36.

Mastroianni, A. (2006). Liability, Regulation and Policy in Surgical Innovation: The Cutting Edge of Research and Therapy. Health Matrix: The Journal of Law-Medicine, 16(2), 351.

Mastroleo, I., \& Holzer, F. (2018). New non-validated practice: a refined definition of innovation in traditional research ethics. Manuscript under review. Buenos Aires. 
Ministerio de Salud Argentina (MSAL) (2011). Resolución 1480/2011. Guía para Investigaciones con Seres Humanos., http://www.uba.ar/archivos_secyt/image/Resolucion1480-11\%20Naci\%C3\%B3n.pdf National Bioethics Advisory Commission (NBAC) (2001). Ethical and Policy Issues in Research Involving Human Participants. Report and Recommendations of the National Bioethics Advisory Commission, https://bioethicsarchive.georgetown.edu/nbac/human/overvol1.pdf

National Commission for the Protection of Human Subjects of Biomedical and Behavioral Research (National Commission). (1978). The Belmont Report: Ethical Principles and Guidelines for the Protection of Human Subjects of Research. US Government Printing Office.

Palacios-González, C., \& Medina-Arellano, M. D. J. (2017a). Mitochondrial replacement techniques and Mexico's rule of law: on the legality of the first maternal spindle transfer case. Journal of Law and the Biosciences, 4(1), 50-69.

Palacios-González, C., \& Medina-Arellano, M. D. J. (2017b). Author's Response to Peer Commentaries: Mexico's rule of law and MRTs. Journal of Law and the Biosciences.

Pontifical Academy for Life (2000). The Declaration on the Production and the Scientific and the Scientific and Therapeutic use of Human Embryonic Stem Cells. Rome: The Vatican. Rassmussen (2015). "Moratorium" on use and asilomar conference. Chichester: John Wiley and Sons.

Rosemann, A., (2013). Medical Innovation and National Experimental Pluralism: Instights from clinical Stem Cell Research and Applications in China. The London School of Economics and Political Sciences BioSocieties 8(1), 58-74. 
Rosemann, A., Bortz, G., \& Vasen, F. (2018). Regulatory developments for nonhematopoietic stem cell therapeutics: perspectives from the EU, the USA, Japan, China, India, Argentina and Brazil. In X. D. Chen (Ed.), A Roadmap to non-Hematopoietic Stem Cell-based Therapeutics: From the Bench to the Clinic. Amsterdam: Elsevier Academic Press.

Sugarman, J. (2012). Questions Concerning the Clinical Translation of Cell-Based Interventions under an Innovation Pathway. The Journal of Law, Medicine \& Ethics, 40(4), 945-950. https://doi.org/10.1111/j.1748-720X.2012.00723.x

Taylor, P. L. (2010). Overseeing Innovative Therapy without Mistaking It for Research: A Function-Based Model Based on Old Truths, New Capacities, and Lessons from Stem Cells. The Journal of Law, Medicine \& Ethics, 38(2), 286-302. https://doi.org/10.1111/j.1748720X.2010.00489.x

World Health Organization, \& Council for International Organizations of Medical Sciences. (2016). International ethical guidelines for health-related research involving humans.

Geneva: Council for International Organizations of Medical Sciences.

World Medical Association (WMA). (2013, October 19). Declaration of Helsinki. Ethical Principles for Medical Research Involving Human Subjects. Retrieved from http://www.wma.net/en/30publications/10policies/b3/index.html Zhang, J. et al. (2016). First Live Birth Using Human Oocytes Reconstituted by Spindle Nuclear Transfer for Mitochondrial DNA Mutation Causing Leigh Syndrome, 106 Fertil. Steril. E375-e376. 


\section{Previous publications disclosure}

The present chapter is based and incorporates parts of the following previous work:

Holzer, F. S., \& Mastroleo, I. (2018). Ethical Aspects of Precision Medicine: An Introduction to the Ethics and Concept of Clinical Innovation. In H.-P. Deigner \& M. Kohl (Eds.), Precision Medicine (pp. 1-19). London: Academic Press-Elsevier.

https://doi.org/10.1016/B978-0-12-805364-5.00001-9

Mastroleo, I., \& Holzer, F. (2018). New non-validated practice: a refined definition of innovation in traditional research ethics. Version submitted to Hastings Center Report on 16th March. Revised version submitted to Journal of Law, Medicine and Ethics on 11th December.

\section{Acknowledgments}

We are extremely grateful to an anonymous reviewer, Florencia Luna, Eduardo Rivera López, Diana Salmún, and the members of the Work in Progress (WIP) Seminar of FLACSO Bioethics Program for valuable comments and suggestions.

\section{Financial Support}

This publication has been made possible thanks to financial support by CONICET Argentina, the German DAAD, the Biothera foundation, as well as the Brocher foundation. 
Table of contents

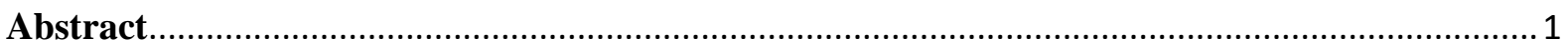

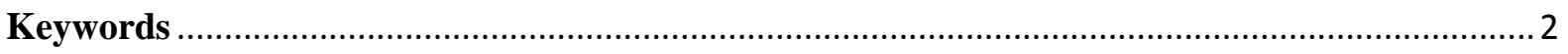

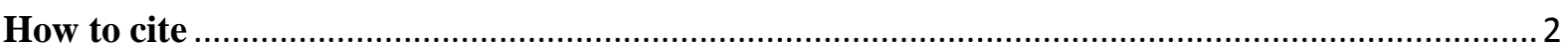

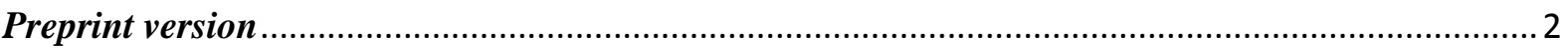

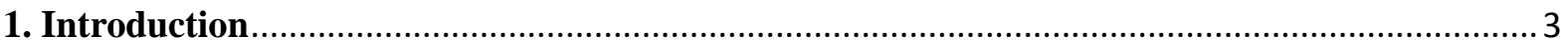

2. Exemplary cases of innovation and its context in Latin America .................................... 6

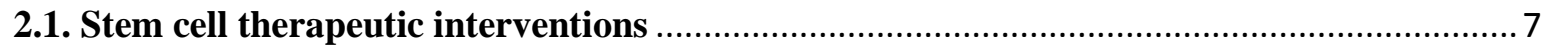

2.2. Genome editing therapeutic interventions .......................................................... 8

2.3. Mitochondrial replacement techniques............................................................ 10

2.4. Genome sequencing as diagnostic tools for individual patients .................................... 13

2.5. Context in Latin America: the hidden battle hypothesis, effective regulation and the

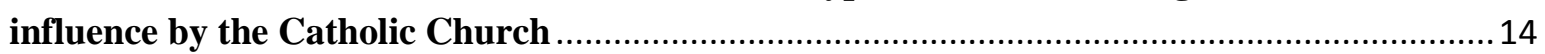

3. Definition: What is innovation as new non-validated practice? ........................................ 16

3.1. Traditional research ethics distinction between research, validated practice and innovation (non-validated practice) ........................................................................ 17

3.2. Levine's definition of non-validated practice .................................................... 21

3.3. Innovative care as new non-validated practice ................................................... 22

Table 1. Medical practice characterized by validation and novelty ......................................23

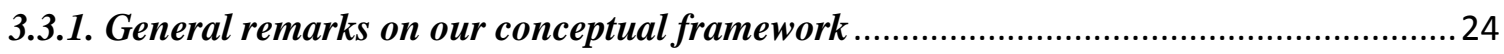

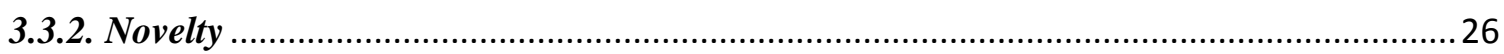

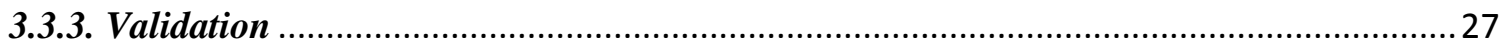

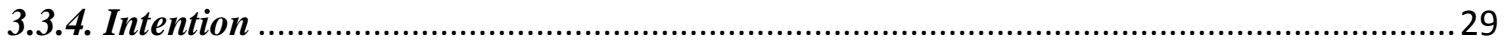

4. Justification: What is the ethical justification of innovation as new non-validated practice?.31

5. Regulation: What are the basic ethical principles of responsible innovation as new non-

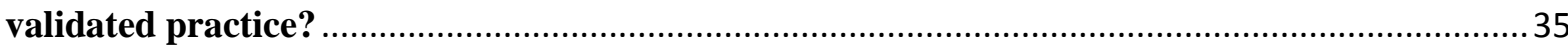

6. Conclusion: What is the importance of responsible innovation as new non-validated practice

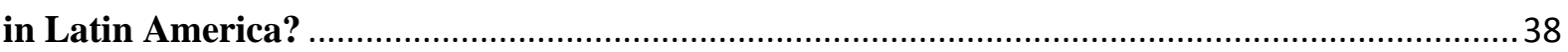

6.1. Recommendations for doctors, individual patients and surrogates ............................40

6.2. Recommendations for ethics committees ....................................................... 42

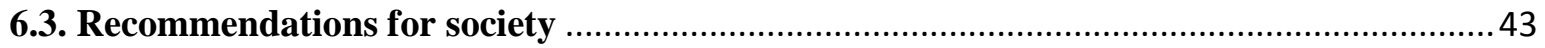

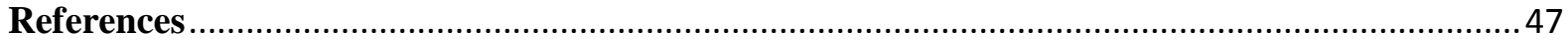

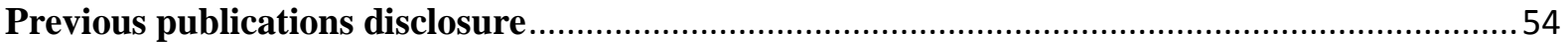

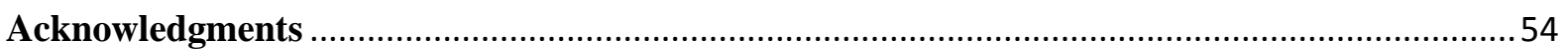

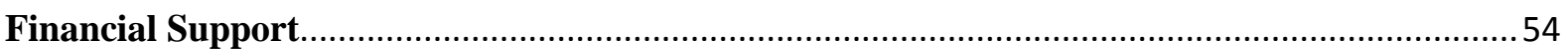


